Recibido: 30/09/2019 --- Aceptado: 06/11/2019 --- Publicado: 15/03/2020

\title{
COMUNICACIÓN PARA LA SALUD: APROXIMACIONES EPIDEMIOLÓGICAS Y SOCIOCULTURALES AL CUERPO-ENFERMO DE LAS MUJERES CON CÁNCER DE MAMA
}

\section{COMMUNICATION FOR HEALTH: EPIDEMIOLOGICAL AND SOCIOCULTURAL APPROACHES TO THE SICK-BODY OF WOMEN WITH BREAST CANCER}

Ester Cofré Soto ${ }^{\mathbf{1}}$ : Universidad Austral de Chile y Universidad de La Frontera. ecofre278@gmail.com

\section{RESUMEN}

Este trabajo se enmarca en los estudios de la comunicación para la salud, específicamente en la necesidad de una sistematización de la información epidemiológica sobre patología de mamas en la región de La Araucanía para realizar un diseño comunicacional focalizado y pertinente a la población de mujeres y sus contextos sociales y culturales, con el propósito de crear conciencia en el autoexamen, los factores de riesgo, los controles periódicos, etc. En este sentido, se pretende retomar la tradición interdisciplinaria de la comunicación para la salud, en la cual se conjugan las estrategias formales de la comunicación con los discursos y prácticas de los actores participantes, en este caso las mujeres de la región de La Araucanía. El objetivo principal de esta investigación es analizar las nociones de cuerpo y enfermedad desde una perspectiva crítica, que permita comprender mejor el contexto social y cultural de las mujeres. Lo anterior, junto a los antecedentes epidemiológicos del cáncer de mamas en la región de La Araucanía, constituyen las bases para pensar un diseño comunicacional situado, pertinente y eficiente.

PALABRAS CLAVE: Comunicación - Salud - cáncer - cuerpo - representaciones enfermedad - epidemiología.

\section{ABSTRACT}

This work is part of the studies of communication for health, specifically in the need for a systematization of epidemiological information on breast pathology in the region of La Araucanía to carry out a focused and relevant communicational design for the population of women and their social and cultural contexts, with the purpose of creating awareness in self-examination, risk factors, periodic controls, etc. In this

\footnotetext{
${ }^{1}$ Ester Cofré Soto: Matrona de la Unidad de Patología de Mamas del Hospital Regional de Temuco Harnán Henríquez Aravena. Estudiante del Doctorado en Comunicación Universidad Austral de Chile y Universidad de La Frontera. ecofre278@gmail.com
} 
sense, the intention is to revisit the interdisciplinary tradition of communication for health, in which the formal communication strategies are combined with the discourses and practices of the participating actors, in this case women from the Araucanía region. The main objective of this research is to analyze the notions of body and disease from a critical perspective, which allows a better understanding of the social and cultural context of women. The above, together with the epidemiological background of breast cancer in La Araucanía region, constitute the basis for thinking about a located, pertinent and efficient communicational design.

KEY WORDS: Communication - Health - cancer - body - representations - disease - epidemiology.

\section{COMUNICAÇÃO PARA SAÚDE: APROXIMAÇÕES EPIDEMIOLÓGICAS E SOCIOCULTURAIS AO CORPO-ENFERMO DAS MULHERES COM CÂNCER DE MAMA}

\section{RESUME}

Este trabalho se enquadra nos estudos da comunicação para a saúde, especificamente na necessidade de uma sistematização da informação epidemiológica sobre patologia de mamas na região da Araucanía para realizar um desenho comunicacional focalizado e pertinente à população de mulheres e seus contextos sociais e culturais, com o propósito de criar consciência em um alto exame, os fatores de risco, os controles periódicos, etc. Neste sentido, pretende-se retomar a tradição interdisciplinaria da comunicação para a saúde, na qual se conjugam as estratégias formais de comunicação com os discursos e práticas dos atores participantes, neste caso as mulheres da região da Araucania. O objetivo principal desta investigação é analisar as noções de corpo e enfermidade desde uma perspectiva crítica, que permita compreender melhor o contexto social e cultural das mulheres. $O$ anterior, junto aos antecedentes epidemiológicos do câncer de mama na região da Araucania, constitui as bases para pensar em um desenho comunicacional situado, pertinente e eficiente.

PALAVRAS CHAVE: Comunicação - Saúde - câncer - representações enfermidade - epidemiologia.

\section{Cómo citar el artículo:}

Cofré Soto, E. (2020). Comunicación para la salud: aproximaciones epidemiológicas y socioculturales al cuerpo-enfermo de las mujeres con cáncer de mama. [Communication for health: epidemiological and sociocultural approaches to the sickbody of women with breast cancer]. Revista de Comunicación de la SEECI, 51, 169183. doi: http://doi.org/10.15198/seeci.2020.51.169-183

Recuperado de http://www.seeci.net/revista/index.php/seeci/article/view/620 
Cofré Soto, E. Comunicación para la salud: aproximaciones epidemiológicas y socioculturales al cuerpo-enfermo de las mujeres con cáncer de mama

\section{INTRODUCCIÓN}

\subsection{Antecedentes epidemiológicos generales}

El cáncer es una de las principales causas de morbilidad y mortalidad en el mundo. Según la Organización Mundial para la Salud (OMS), el cáncer representa aproximadamente el $15 \%$ de las muertes del mundo; siendo el pulmonar $(19 \%)$, el hepático $(9 \%)$, el colorrectal $(9 \%)$, el gástrico $(8 \%)$ y el mamario ${ }^{2}(7 \%)$, los que causan el mayor número de fallecimientos (OMS, 2017).

Por su parte en Chile, de acuerdo al estudio de la Asociación de Isapres de Chile (2017), "el cáncer es la segunda causa de muerte en nuestro país, después de las enfermedades cardiovasculares. 1 de cada 4 muertes producidas en Chile es causada por tumores, falleciendo algo más de 26 mil personas al año por esta causa". Esta información es sustentada por la Dirección de Estadísticas e Información en Salud (DEIS), la cual añade que "en algunas regiones del país ya es la primera causa de muerte, pues los factores de riesgo cardiovasculares están siendo mejor controlados"; de modo que según estimaciones del Ministerio de Salud (MINSAL) hacia el 2020 esta enfermedad será la primera causa de muerte en el país". Finalmente, este estudio muestra que entre "Los cáncer más tratados por GES son el cáncer de mama (37\%)".

Pese a todo lo anterior, lamentablemente, según este mismo estudio "Chile no cuenta con buenos registros estadísticos respecto a las personas afectadas por cáncer, lo que dificulta construir programas de sanidad pública y distribuir recursos"; siendo el problema más serio el hecho que no disponemos de información "respecto a las personas afectadas por cáncer, el tipo de cáncer y sexo y edad de los pacientes, así como tampoco la localidad de dichos pacientes" pese a facilidades para la recopilación de información como las apuntadas por Herrero-Curiel (2011, p. 116) o para la difusión, las citadas por Marta-Lazo y Gabelas-Barroso (2013, p. 16) con los niveles de influencia apuntados por García Lirios et al $(2013$, p. 61) sobre principios como los que sostienen a Domínguez $(2018$, p. 56$)$ y a Cardoso, Bobadilla y Pérez (2018, p. 91), aunque siempre teniendo en cuenta matizaciones a la sociedad digital y su comunicación como las planteadas por Aladro $(2011$, p. 86).

En este sentido, el objetivo del Programa Nacional de Cáncer es "Disminuir la tasa de mortalidad, mediante la pesquisa temprana, diagnóstico y tratamiento oportunos, adecuados y de calidad" (Báez, 2017).

Si nos situamos en el ámbito más específico de la investigación "En la mujer, el cáncer de mama es la primera causa de muerte por cáncer a nivel mundial, estimándose 522 mil defunciones en el año 2012, con una tasa estandarizada de mortalidad de 12,9 por 100.000 mujeres y una tasa de incidencia de 43,3 por 100.000 mujeres, lo que corresponde a $25,2 \%$ de la incidencia de cáncer en este 2 El año 2015 "se atribuyeron a esta enfermedad 8,8 millones de defunciones", de las cuales 571000
corresponden al cáncer mamario; según las estadísticas de la OMS (2017).

Revista de Comunicación de la SEECI. 15 marzo, 2020 / 15 julio, 2020, nº 51, 169-183 
grupo" (Icaza, Núñez y Bugueño, 2017). Uno de los aspectos relevantes de este estudio es que "El riesgo relativo de mortalidad por cáncer de mama en mujeres en Chile a nivel comunal, se asoció positivamente con educación y negativamente con el porcentaje de ruralidad" (Icaza, Núñez y Bugueño, 2017, p. 111). Estas asociaciones han sido registradas también a nivel internacional (Singh, Williams, Siahpush y Mulhollen, 2011). Según el estudio "Esto podría explicarse por la mayor prevalencia de factores de riesgo de tipo hormonal en mujeres residentes en comunas urbanas y por diferencias en las etapas de la transición epidemiológica a lo largo del país [aunque] en países desarrollados este mayor riesgo en áreas urbanas se ha trasladado al sector rural, debido a factores relacionados con la detección y acceso a tratamiento oportuno" (Icaza, Núñez y Bugueño, 2017, p. 112).

Los estudios coinciden en que los desafíos son de diferente naturaleza y van desde:

a) Extender la edad de las mamografías.

b) Acreditar los centros de imágenes mamarias.

c) Mejorar la cobertura.

d) Alcanzar indicadores similares a los de la OCDE o países desarrollados.

\subsection{Comunicación para la salud: Un enfoque interdisciplinario}

El ámbito de la comunicación en/para la salud no es nuevo. Se ve afectado igualmente por la falacia información/comunicación apuntada por Abril (2007, p. 59) y por los aspectos sobre comunicación de riesgos citados por Beling Loose y Girardi (2018, p. 220) y Casero-Ripollés (2014, p. 2). De hecho, uno de los hitos fundacionales corresponde al "grupo de comunicaciones terapéuticas" creado en 1972 en el seno de la Asociación Internacional de Comunicación (ICA, por su sigla en inglés) y que en 1975 pasó a llamarse "comunicación para la salud (Health Communications)"; sin embargo, "es débil en las escuelas de comunicaciones y de salud pública de América Latina, donde ambas disciplinas casi no conversan entre sí, salvo en materias muy específicas" (Busse y Godoy, 2016) como si ocurre con la comunicación institucional en lo relativo a los momentos en los que ésta se convierte en necesidad a causa de amenazas a la seguridad (Cancelo Sanmartín y Gadea Aldave, 2013, p. 24). Por otra parte, la experiencia en las universidades estadounidenses muestra los importantes avances de la colaboración entre ambas disciplinas, especialmente en las investigaciones (Alcalay, 1999). Sin embargo, este trabajo "no ha sido sistemático, sino que ha respondido más bien de forma reactiva a la necesidad imperativa de incluir el aspecto de comunicaciones en la promoción de la salud" (Alcalay, 1999, p. 195).

La presente investigación se enmarca en esta línea, de manera que busca articular los saberes de la comunicación y de la salud y desde aquí: (a) abrir un diálogo interdisciplinario en aras del espíritu crítico propugnado por Mora Fernández et al (2018, p. 131), (b) situar la comunicación como un campo que no solamente provee estrategias e instrumentos sino que también permite una comprensión de los procesos de salud, y (3) situar la salud como un hecho comunicativo y cultural, incluso en la realidad comunicativa percibida por Serrano-Puche $(2014$, p. 1). A 
Cofré Soto, E. Comunicación para la salud: aproximaciones epidemiológicas y socioculturales al cuerpo-enfermo de las mujeres con cáncer de mama

modo de síntesis, se trata de estudiar "cómo la ciencia de las comunicaciones adquiere relevancia social aportando a otras áreas del quehacer humano -en este caso a la de la salud- teorías, conceptos y técnicas para mejorar el bienestar de la población" (Alcalay, 1999, p. 195).

En este mismo sentido, se trata de comprender la salud en tanto discurso y práctica que se realiza en los contextos particulares de la comunicación y la cultura; por lo cual es relevante, por una parte, identificar las teorías, modelos y conceptos presentes desde la larga tradición institucionalizada de la comunicación en salud (Mosquera, 2003), tales como:

a) La Teoría del Aprendizaje Social.

b) El Modelo de Creencias en Salud.

c) El Modelo de Difusión de Innovaciones.

d) El Modelo de Comunicación para el Cambio Social.

Como también es importante, de otra parte, identificar los discursos y prácticas de los diferentes actores y agentes participantes, especialmente a través de los distintos medios disponibles como de los niveles de comunicación presentes (Coe, 1998), tales como:

a) Comunicación a nivel interpersonal.

b) Comunicación a nivel colectiva.

c) Comunicación a nivel organizacional.

d) Uso de medios públicos de comunicación.

Lo anterior, específicamente a propósito de la comunicación situada de los riesgos posibles, la detección temprana de los problemas y el acceso oportuno a la información y al tratamiento.

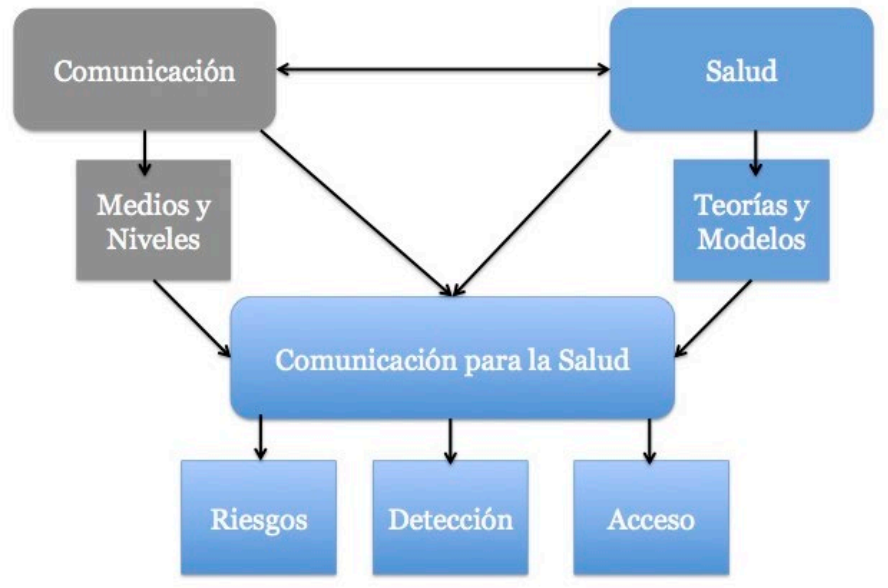

Imagen 1: relaciones entre comunicación y salud.

Fuente: elaboración propia.

\subsection{El cáncer de mama}

El cáncer de mama consiste en el crecimiento anormal y la proliferación acelerada, desordenada e incontrolada de células del epitelio glandular, de los conductos 0 
lobulillos mamarios -esto es, en los tejidos de la mama- con una alta capacidad de diseminación. Se trata, en definitiva, de células que han aumentado enormemente su capacidad reproductiva. Aunque se da tanto en hombres como en mujeres, es poco común en los primeros. Los tipos histológicos de mayor frecuencia son el carcinoma ductal y el carcinoma lobulillar (Minsal, 2015).

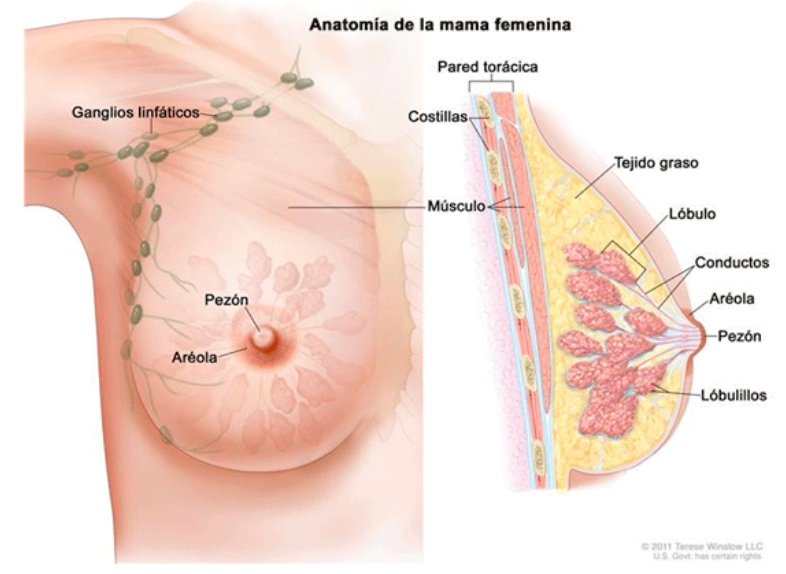

Imagen 2: anatomía de la mama femenina.

Fuente: Santaballa (2017).

Entre los agentes causales se reconocen factores genéticos, familiares y conductuales; siendo del $5 \%$ al $10 \%$ de carácter hereditario y sobre un $85 \%$ esporádicos.

Entre los factores de riesgo de una mujer para el desarrollo del cáncer de mama, encontramos:

a) Los aspectos étnico-raciales. Las evidencias en Estados Unidos muestran mayor incidencia en mujeres blancas que de color (Harris, et al., 2011).

b) La edad. En la mayoría de los casos se desarrolla en mujeres de más de 50 años.

c) Los antecedentes personales de la enfermedad. Si la mujer ha presentado la enferemedad previamente, el riesgo de presentarla es más alto.

d) Los antecedentes familiares de la enfermedad. Es hereditario cuando: (i) hay casos de parientes de primer grado (madre, hermanas e hijos), con cáncer de mamas o de ovarios, en especial antes de los 50 años. Si son dos parienes de primer grado, el riesgo aumenta 5 veces promedio; (ii) muchos parientes cercanos (abuelos, tíos y tías, sobrinos y sobrinas, nietos y primos) con cáncer de mamas o de ovarios, especialmente antes de 50 años.

e) La predisposición genética. Existen varios genes hereditarios vinculados con el aumento del riesgo de la enfermedad. Los genes BRCA1 y BRCA2 son las mutaciones conocidas más frecuentes.

f) Los antecedentes personales de cáncer de ovario.

g) La menstruación temprana y menopausia tardía. 
h) La edad y duración del embarazo. Las mujeres que han tenido su primer embarazo después de los 35 años o que nunca han tenido un embarazo de término, tienen mayor riesgo de la enfermedad.

i) El uso de terapia hormonal de reemplazo después de la menouapsia, aumenta el riesgo.

j) El uso de anticonceptivos orales o pastillas anticonceptivos, aumentan levemente el riesgo. Esto aún es objeto de investigación.

k) La hiperplasia típica de la mama. Este diagnóstico aumenta el riesgo.

l) La densidad de la mama. El tejido mamario denso puede dificultar la detección de un tumor en una mamografía.

Por otro lado, entre los factores asociados al estilo de vida, encontramos:

a) El peso. La obesidad favorece en cáncer.

b) La actividad física. La disminucuón de ella se asocia con el mayor riesgo de aparición del cáncer y reaparición luego del tratamiento.

c) El alcohol. Consumir una o dos bebidas alcohólicas (cerveza, vino y licor) por día, se asocia con el mayor riesgo de aparición del cáncer y reaparición luego del tratamiento.

d) Los alimentos. Si bien no hay estudios confiables sobre la relación de ciertos alimentos y la reducción de los riesgos, comer más frutas y verduras y menos grasas animales se asocia con beneficios para la salud.

Otro tipo de factores de riesgo relevantes para esta investigación son los de carácter socioeconómico, según los cuales las mujeres de mayor nivel socioeconómico de los diferentes grupos étnicos tienen un mayor riegso de desarrollar cáncer de mamas que las mujeres de niveles socioeconómicos más bajos de los mismos grupos. Hasta ahora se desconocen los motivos de estas diferencias, sin embargo pueden relacionarse a variaciones en la dieta y las exposiciones ambientales. Por otra parte, a lo anterior se debe señalar que en el caso de las mujeres con mayor nivel socioeconómico el diagnóstico es más temprano y, por lo tanto, es mayor la sobrevida (Asco, 2018).

Finalmante, otro factor de riesgo corresponde a la exposición a radiación ionizante a edades tempranas, lo cual puede aumentar el riesgo de la enfermedad.

Aunque las recomendaciones no coinciden, los organismos internacionales más relevantes sobre esta enfermedad, están de acuerdo en que iniciar la mamografía de detección temprana -de carácter anual- a los 40 años puede salvar vidas. De hecho, según el Departamento de Salud y Servicios Humanos de Estados Unidos (HHS, por sus siglas en inglés), las mujeres de entre 40 y 74 años que se hacen mamografías de detección temprana tienen un menor riesgo de morir de cáncer de mama que las mujeres que no se las realizan.

Por su parte, el Colegio Americano de Radiología (ACR, por sus siglas en inglés) y la Sociedad Radiológica de Norteamérica (RSNA, por sus siglas en inglés) recomiendan que, comenzando a los 40 años, las mujeres que presentan un riesgo promedio de cáncer de mama se sometan a una mamografía de detección temprana 
cada año. La Sociedad Americana del Cáncer (ACS, por sus siglas en inglés) recomienda que las mujeres entre 40 y 44 años consideren hacerse las pruebas de detección temprana.

Para la ACS, la mamografía de detección temprana debería comenzar a los 45 y hacerse cada año hasta los 55; luego de lo cual pueden realizarlas año por medio. El Grupo de Trabajo de Servicios Preventivos de los Estados Unidos (USPSTF) recomienda que los exámenes de detección temprana para mujeres con riesgo promedio deberían comenzar a los 50 años y hacerse año por medio. El Instituto Nacional del Cáncer (NCI, por sus siglas en inglés) aconseja a las mujeres que han tenido cáncer de mama -y a aquellas que presentan alto riesgo debido a una historia familiar de cáncer de mamaque busquen consejos médicos profesionales con respecto a la frecuencia de los exámenes y sobre si deben comenzar antes de los 40 . La edad en la cual se debe dejar de hacer la mamografía no ha sido establecida firmemente, pero en general, se piensa que la detección temprana debería continuar mientras la mujer se encuentre en buen estado de salud, independientemente de la edad.

Las mujeres con alto riesgo de cáncer de mama deberían seguir lineamientos diferentes. De acuerdo a las recomendaciones de la Sociedad Americana del Cáncer, la mayoría de las mujeres con alto riesgo deberían comenzar la detección temprana con una Resonancia Magnética Nuclear de Mamas y una mamografía a los 30 años y continuar haciéndolo. Algunas mujeres con alto riesgo podrían comenzar la detección temprana con Resonancia Magnética Nuclear de Mamas a los 25 años. Es importante recordar que la mayoría de los cánceres de mama ocurren en mujeres sin factores de riesgo.

Para llevar a cabo la detección temprana de I cáncer de mama, se considera principalmente:

a) Examen clínico de mamas. El médico palpa cuidadosamente las mamas y las axilas para detectar bultos o cualquier otra cosa inusual. Las mujeres pueden realizar un autoexamen.

b) Mamografía. Examen con rayos X. Generalmente se toman dos imágenes de cada mama, una imagen generando una vista desde la parte superior hasta la inferior y otra produciendo una vista en ángulo de lado a lado.

\subsection{El cuerpo en contexto sociocultural}

En el presente trabajo nos interesa comprender críticamente las nociones de cuerpo y enfermedad, es decir no solo en sus dimensiones biomédicas, es muy relevante considerar el contexto psicológico, social y cultural de las mujeres con cáncer de mama, específicamente las formas de autorrepresentación que ellas tienen sobre su cuerpo-enfermo. En este sentido, necesitamos un enfoque apropiado para observar estas condiciones, para lo cual se ha recurrido a una bibliografía particular que, obviamente, está en proceso de búsqueda.

En primer lugar, se trata de un objeto de estudio poco recurrente en las ciencias sociales, a pesar de su presencia: "La sociología contemporánea tiene poco que decir 
acerca del hecho más obvio de la existencia humana, a saber, que los seres humanos tienen, y en cierta medida son, cuerpos" (Turner, 1989, p. 57).

En segundo lugar, es importante para un estudio crítico sobre el cuerpo en la sociedad y la cultura, como éste, saber que no se trata de escribir un tratado sobre la sociedad y la fisiología, sino de dar cuenta de una serie de dimensiones y aspectos implicados (Turner, 1989, p. 66 y 67):

1) Para el individuo y el grupo, el cuerpo es simultáneamente un entorno (parte de la naturaleza) y un medio del yo (parte de la cultura).

2) Una diferenciación entre el cuerpo de las poblaciones y el cuerpo de los individuos [donde] el cuerpo del individuo es regulado y organizado en interés de la población.

3) El cuerpo yace en el centro de las luchas políticas.

4) La mayor parte de las formas de teorización sociológica establece una drástica separación entre el yo y el cuerpo.

Siguiendo con lo anterior, Le Breton "La presentación física parece valer socialmente como presentación moral" (2002, p. 82), en el sentido de un código moral que permite poner en escena las apariencias para la mirada evaluadora y el prejuicio social de los otros, basado especialmente en detalles de la vestimenta, el cuerpo o la cara. Se trata de estereotipos que se establecen desde las apariencias físicas y "se transforman rápidamente en estigmas, en signos fatales de defectos morales o de pertenencia a una raza" (ídem).

Por lo antes dicho, es importante considerar la magnitud de los aspectos físicos del cuerpo-enfermo, pues no solo se trata de una condición fisiológica, sino también moral. No solo es un cuerpo-enfermo objeto de estereotipos, sino de evaluación, del juicio social del grupo (la familia, los amigos, los compañeros de trabajo, los vecinos). Es un cuerpo-enfermo observado y a la vez valorado y enjuiciado.

Por otro lado, como en esta investigación se trata de un cuerpo-enfermo, es decir el cuerpo de la mujer con cáncer de mama, es especialmente interesante considerar la manera en que la mujer "acepta o niega su enfermedad, la forma en que la interpreta y presta significación a sus aspectos más absurdos [porque] todo esto constituye una de las significaciones más esenciales de la enfermedad" (Foucault, 1984, p. 66).

En este sentido, la autoobservación del cuerpo-enfermo es otra condición clave, porque además de la aceptación y rechazo hay un proceso de interpretación constante de todo lo que acontece cotidianamente en dicho cuerpo. La autoobservación es continua.

Por su parte, como en la investigación el objetivo es dar cuenta del cuerpo enfermo y asumir esta condición, los conceptos de cuidado y autocuidado tienen un rol relevante, no solo en un sentido preventivo, sino también curativo; donde cuidar es entendido como "un acto de vida que permite que la vida continúe y se desarrolle $y$, de ese modo, luchar contra la muerte; también es mantener la vida asegurando la 
Cofré Soto, E. Comunicación para la salud: aproximaciones epidemiológicas y socioculturales al cuerpo-enfermo de las mujeres con cáncer de mama

satisfacción de un conjunto de necesidades indispensables para la vida" (Colliere, 1993, p. 5). En tanto que el autocuidado se presenta como "la contribución de la persona a su propia existencia, es una actividad aprendida y orientada hacia un objetivo para regular los factores que afectan el propio desarrollo y funcionamiento en beneficio de su visa, salud o bienestar" (Orem, 1999, p. 177).

De esta manera, la autoobservación sobre el cuerpo-enfermo obedece a un propósito mayor que es el cuidado, es decir una condición que impone a la observación un fin individual y colectivo, porque va acompañado de la observación médica.

\section{OBJETIVOS}

\subsection{General}

Comprender las nociones de cuerpo y enfermedad desde una perspectiva crítica, junto a los antecedentes epidemiológicos, como parte del contexto social y cultural de las mujeres con cáncer de mama en la región de La Araucanía; para pensar un diseño comunicacional situado, pertinente y eficiente.

\subsection{Específicos}

a) Identificar las características epidemiológicas del cáncer de mamas en las región de La Araucanía.

b) Analizar las nociones de cuerpo y enfermedad desde una perspectiva crítica.

c) Pensar un diseño comunicacional situado, pertinente y eficiente para incidir en la detección temprana y el acceso al tratamiento oportuno, adecuado y de calidad del cáncer de mamas.

\section{METODOLOGÍA}

Como no existe información específica y actualizada publicada, se accedió a las bases de datos de la Unidad de Patología de Mamas del Hospital Regional Hernán Henríquez Aravena, lo cual permitió contar con antecedentes epidemiológicos específicos de la región ${ }^{3}$.

Tabla 1. Antecedentes epidemiológicos de la región de La Araucanía, Chile.

\begin{tabular}{|l|c|c|c|}
\hline \multicolumn{1}{|c|}{ Año } & No pacientes nuevas & No pacientes con cáncer & No pacientes sin cáncer \\
\hline 2016 & 1146 & 215 & 931 \\
\hline 2017 & 978 & 258 & 720 \\
\hline 2018 & 1243 & 255 & 988 \\
\hline Total del trienio & 3367 & 728 & 2639 \\
\hline
\end{tabular}

Fuente: elaboración propia.

\footnotetext{
${ }^{3}$ Información obtenida de la base de datos de la Unidad de Patología de Mamas del Hospital Hernán Henríquez Aravena de Temuco, sólo para uso académico.
} 
De lo anterior se desprende, por ejemplo, que durante los últimos 3 años se han presentado 728 nuevos casos de cáncer de mamas en la región. Esto significa que el $22 \%$ de las consultas nuevas en los últimos 3 años resultan en un diagnóstico de cáncer de mamas. Una de las razones que explican este aumento progresivo, corresponde a las políticas de detección temprana.

Las estadísticas coinciden con los datos a nivel nacional, según los cuales existe un " $25,2 \%$ de incidencia de cáncer en este grupo" (Icaza, Núñez y Bugueño, 2017). Asimismo, se ratifica la falta de información más detallada y certera, de acuerdo al tipo de información que se logró obtener para estos datos.

Ahora bien, si consideramos solo las 716 nuevas consultas del primer semestre del año 2019, 128 corresponden a casos nuevos de cáncer de mamas. De las nuevas consultas, en 106 casos corresponden a mujeres hasta 35 años, 7 de las cuales resultaron con diagnóstico de cáncer de mamas. De las 610 restantes, 121 corresponden a casos de cáncer. Entre 36 y 70 años, los casos de cáncer son 97 de un total de 548 nuevas consultas en este grupo etáreo. De más de 70 años hay 62 nuevas consultas, de las cuales 24 resultaron con diagnóstico de cáncer.

De esta manera, podemos observar que hasta los 35 años el número de consultas es bajo, puesto que representa solo el $15 \%$, considerando que en este tramo de edades la consulta podría resultar temprana, obviamente dependiendo de las características del cáncer. Esto también podría estar asociado a una menor preocupación.

Por otra parte, entre los 36 y 70 años se concentra el $77 \%$ de las consultas, con un $18 \%$ de casos de diagnósticos que resultan en cáncer, pero este grupo, al mismo tiempo, representa el $76 \%$ del total de casos de cáncer durante el primer semestre de 2019. Lo anterior implica la necesidad de focalizar el trabajo clínico y comunicacional (promoción de la salud) en este grupo etáreo, considerando sus particularidades sociales y culturales.

En este sentido, no solo resultan de interés las correlaciones estadísticas que se han realizado, sino que también las narrativas de las propias mujeres. Las entrevistas realizadas hasta ahora, dan cuenta de algunas narrativas de especial interés para el trabajo. Entenderemos la entrevista como "una conversación sistematizada que tiene por objeto obtener, recuperar y registrar las experiencias de vida guardadas en la memoria de la gente [con una] Riqueza informativa en las palabras y las interpretaciones" (Sautu et al., 2005, pp. 48 y 49).

A continuación citaremos algunos ejemplos, como parte del tipo de corpus de análisis que se utilizará, correspondiente a ciertas narrativas autobiográficas de las mujeres expresadas en las entrevistas ${ }^{4}$ :

${ }^{4}$ Citas extraídas de entrevistas clínicas con pacientes del Hospital Regional Hernán Henríquez Aravena, reservándose la identidad por razones bioéticas; siendo sólo para uso académico. 
Cofré Soto, E. Comunicación para la salud: aproximaciones epidemiológicas y socioculturales al cuerpo-enfermo de las mujeres con cáncer de mama

- "Cuando supe que tenía cáncer, hablé con mi pareja y le dije que se podía ir nomás"(41 años, casada).

- "Si señorita, me voy a sacar toda la mama, total no tengo pareja" (50 años, separada).

- "Yo me sacaría ambas mamas, total ya amamanté a mis hijos y cumplieron su función"(45 años, casada).

- "No me gustaría hacerme la radioterapia para no darle problemas a mis hijas" (70 años, viuda).

- "No sé si realizarme la quimioterapia, porque se me caerá el pelo" (43 años, casada).

Estos ejemplos refieren varios aspectos que serán utilizados como categorías para el trabajo de investigación de la tesis, a saber:

Tabla 2. Narrativas autobiográficas de mujeres con cáncer.

\begin{tabular}{|c|c|c|}
\hline Narrativa autobiográfica & Aspecto & Categoría \\
\hline $\begin{array}{l}\text { "Cuando supe que tenía cáncer, } \\
\text { hablé con mi pareja y le dije que se } \\
\text { podía ir nomás"( } 41 \text { años, casada). }\end{array}$ & $\begin{array}{c}\text { Relación del cuerpo-enfermo } \\
\text { con los vínculos afectivos con } \\
\text { otros }\end{array}$ & $\begin{array}{l}\text { Cuerpo-enfermo como } \\
\text { relación con otros }\end{array}$ \\
\hline $\begin{array}{l}\text { "Si señorita, me voy a sacar toda la } \\
\text { mama, total no tengo pareja"( } 50 \\
\text { años, separada). }\end{array}$ & $\begin{array}{l}\text { Relación del cuerpo-enfermo } \\
\text { con una falta de vínculos } \\
\text { afectivos de pareja }\end{array}$ & \multirow[b]{2}{*}{$\begin{array}{l}\text { Cuerpo-enfermo como no- } \\
\text { relación con otros }\end{array}$} \\
\hline $\begin{array}{l}\text { "Yo me sacaría ambas mamas, total } \\
\text { ya amamanté a mis hijos y } \\
\text { cumplieron su función"( } 45 \text { años, } \\
\text { casada) }\end{array}$ & $\begin{array}{c}\text { Relación del cuerpo-enfermo } \\
\text { con una falta de vínculos } \\
\text { materno-afectivos }\end{array}$ & \\
\hline $\begin{array}{l}\text { "No me gustaría hacerme la } \\
\text { radioterapia para no darle } \\
\text { problemas a mis hijas"(70 años, } \\
\text { viuda) }\end{array}$ & $\begin{array}{l}\text { Relación del cuerpo-enfermo } \\
\text { con crisis materno-afectivos }\end{array}$ & $\begin{array}{l}\text { Cuerpo-enfermo como no- } \\
\text { crisis con otros }\end{array}$ \\
\hline $\begin{array}{l}\text { "No sé si realizarme la } \\
\text { quimioterapia, porque se me caerá } \\
\text { el pelo"( } 43 \text { años, casada) }\end{array}$ & $\begin{array}{l}\text { Relación del cuerpo-enfermo } \\
\text { con la estética corporal }\end{array}$ & $\begin{array}{l}\text { Cuerpo-enfermo como } \\
\text { cuerpo estético }\end{array}$ \\
\hline
\end{tabular}

Fuente: elaboración propia.

\section{DISCUSIÓN Y CONCLUSIONES}

Considerando los datos estadísticos, que permiten situar epidemiológicamente el problema, se pretende más adelante profundizar en las características sociales y culturales de las mujeres de los dos grupos etáreos aquí trabajados, a saber hasta 35 años y entre 36 y 70 años, a través de entrevistas focalizadas y en profundidad; lo cual permitirá comprender la incidencia de las relaciones de las mujeres con su cuerpo en la motivación de la consulta y el tratamiento.

En tanto, los resultados del análisis de las narrativas autobiográficas de las mujeres, dan cuenta de aquellos nudos críticos que a partir de sus autorrepresentaciones permiten establecer cómo el modo de comprender el cuerpo- 
Cofré Soto, E. Comunicación para la salud: aproximaciones epidemiológicas y socioculturales al cuerpo-enfermo de las mujeres con cáncer de mama

enfermo puede relacionarse empíricamente con la forma de tratar(se) la enfermedad.

Si bien los ejemplos utilizados aquí son solo paradigmáticos y casuísticos, permiten tener una base para avanzar posteriormente en la discusión teórica y el diseño metodológico.

Por ahora, podemos observar relaciones del cuerpo-enfermo:

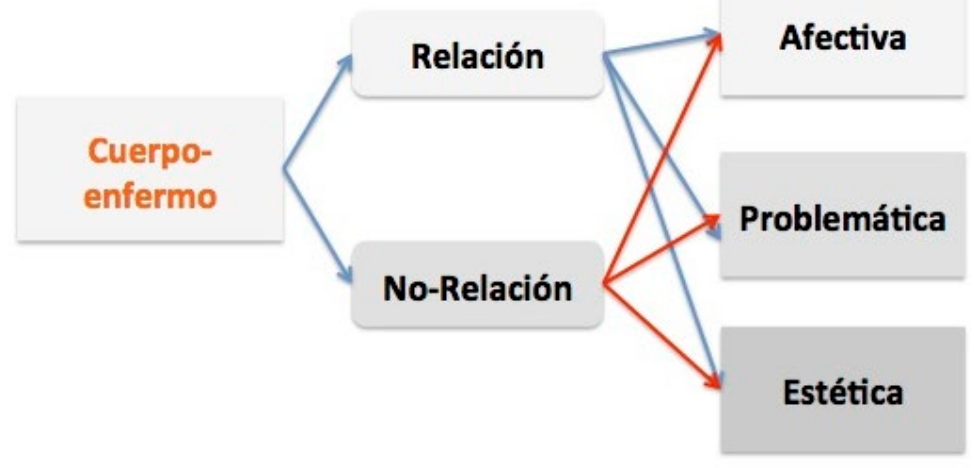

Imagen 3: Relaciones del cuerpo-enfermo, según narrativas.

Fuente: elaboración propia.

\section{REFERENCIAS}

Aladro, E. (2011). La Teoría de la Información ante las Nuevas Tecnologías. Cuadernos de Información y Comunicación, 16, 83-93.

Abril, G. (2007). La información como formación cultural. Cuadernos de Información y Comunicación, 12, 59-73.

Alcalay, R. (1999). La comunicación para la salud como disciplina en las universidades estadounidenses. Rev Panam Salud Publica/Pan Am J Public Health, 5(3), 192-196.

Asociación de Isapres de Chile (2017). Recuperado de http://www.isapre.cl/PDF/Informe\%20Cancer2017.pdf

Báez, L. (2017). Actualización Programa Nacional de Cáncer. Recuperado de http://www.ispch.cl/sites/default/files/Actualizacion Programa Nac de Cancer.pdf

Beling Loose, E. y Tourinho Girardi, I. (2018). Antes do desastre: notas a respeito do Jornalismo, da comunicação de riscos, da prevenção e do envolvimento cidadão. Mediaciones Sociales, 17, 209-222. 
Cofré Soto, E. Comunicación para la salud: aproximaciones epidemiológicas y socioculturales al cuerpo-enfermo de las mujeres con cáncer de mama

Busse, P. y Godoy, S. (2016). Comunicación y salud. Cuadernos.info, 38, 10-13.

Cancelo Sanmartín, M. y Gadea Aldave, G. (2013). Empoderamiento de las redes sociales en las crisis institucionales. Vivat Academia. Revista de Comunicación, 15(124), 21-33. doi: http://dx.doi.org/10.15178/va.2013.124.21-33

Cardoso, D., Bobadilla, S. \& Pérez, M. A. (2018). Habits of reading in college. Case degree of administration of the Tejupilco professional academic unit. Investigaciones Sobre Lectura, 9, 73-104.

Casero-Ripollés, A., Ortells-Badenes, S. y Doménech-Fabregat, H. (2014). Las competencias profesionales en periodismo: una evaluación comparativa. Historia y Comunicación Social, 18, 53-64.

doi: https://doi.org/10.5209/rev HICS.2013.v18.44311

Coe, G. (1998). Comunicación y promoción de la salud. Revista CHASQUI, 63, 26-29.

Colliere, M. F. (1993). Promover la vida. Madrid: MacGraw-Hill.

Domínguez, A. I. (2018). Fomento de la lectura y la escritura en lenguas indígenas de México: algunas consideraciones. Investigaciones Sobre Lectura, 10, 55-94.

Foucault, M. (1984). Enfermedad mental y personalidad. Barcelona: Paidós.

García Lirios, C.; Carreón Guillén, J.; Hernández Valdés, J.; Bautista Miranda, M. y Méndez Martínez, A. (2013). La cobertura de la prensa en torno a la inseguridad migratoria durante elecciones presidenciales. Revista de Comunicación de la SEECI, 1730), 57-73. doi: http://dx.doi.org/10.15198/seeci.2013.30.57-73

Harris, et al. (2011). Enfermedades de la mama. Cuarta edición. Barcelona: Wolters Kluwen Health España.

Herrero-Curiel, E. (2011). El periodismo en el siglo de las redes sociales. Vivat Academia. Vivat Academia. Revista de Comunicación, 117E, 1113-1128. doi: http://dx.doi.org/10.15178/va.2011.117E.1113-1128

Icaza, G.; Núñez, L. y Bugueño, H. (2017). Descripción epidemiológica de la mortalidad por cáncer de mama en mujeres en Chile. Recuperado de https://scielo.conicyt.cl/pdf/rmc/v145n1/art14.pdf

Le Breton, D. (2002). La sociología del cuerpo, Buenos Aires: Nueva Visión.

Marta-Lazo, C. y Gabelas-Barroso, J. A. (2013). Hábitos de consumo televisivo de ficción entre los universitarios que estudian Comunicación. Revista de Comunicación de la SEECI, 17(31), 14-33.

doi: http://dx.doi.org/10.15198/seeci.2013.31.14-33 
Cofré Soto, E. Comunicación para la salud: aproximaciones epidemiológicas y socioculturales al cuerpo-enfermo de las mujeres con cáncer de mama

Ministerio de Salud de Chile (2015). Guías clínicas AUGE. Recuperado de https://diprece.minsal.cl/wrdprss minsal/wp-content/uploads/2016/12/GPCMAMA-Nov2016.pdf

Mora Fernández, J.; Ortiz, F.; Ávila Solano, B. y Romero Galarza, A. (2018). La LOC y la educación en principios mediante la mediación social ecuatoriana en las prácticas comunicativas digitales. Mediaciones Sociales, 17, 117-133.

Mosquera, M. (2003). Comunicación en Salud: Conceptos, Teorías y Experiencias. Recuperado de http://www.portalcomunicacion.com/obregon/pdf/Mosquera 2003.pdf

Orem, A. R. (1999). Teoría del déficit de autocuidado, en Marriner, T., Modelos y teorías en enfermería, Madrid: Hancourt.

Organización Mundial para la Salud (2017). Recuperado de https://www.who.int/es/news-room/fact-sheets/detail/cancer

Santaballa, A. (2017). Cáncer de mama. Sociedad española de oncología médica. Recuperado de https://seom.org/info-sobre-el-cancer/cancer-de-mama

Sautu, R. et al. (2005). Manual de metodología. Construcción del marco teórico, formulación de los objetivos y elección de la metodología. Buenos Aires: CLACSO.

Serrano-Puche, J. (2014). Vidas conectadas: tecnología digital, interacción social e identidad. Historia Y Comunicación Social, 18, 353-364. doi: https://doi.org/10.5209/rev HICS.2013.v18.44249

Singh G. K., Williams S. D., Siahpush M. \& Mulhollen A. (2011). Socioeconomic, Rural-Urban, and Racial Inequalities in US Cancer Mortality: Part I-All Cancers and Lung Cancer and Part II-Colorectal, Prostate, Breast, and Cervical Cancers. Recuperado de http://www.pubmedcentral.nih.gov/articlerender.fcgi?artid=3307012\&tool=pmcen trez\&rendertype $=$ abstract

Sociedad Estadounidense de Oncología Clínica (2018). Cáncer de mama. Factores de riesgo y prevención. Recuperado de https://www.cancer.net/es/tipos-dec\%C3\%A1ncer/c\%C3\%A1ncer-de-mama/factores-de-riesgo-y-prevenci\%C3\%B3n

Turner, B. (1989). El cuerpo y la sociedad. Exploraciones en teoría social. México DF: Fondo de Cultura Económica. 